\title{
On the Science of Indian Rural Development
}

\author{
Bruce Alberts
}

Received: 19 December 2011/ Accepted: 22 December 2011/Published online: 19 January 2012

(C) NAAS (National Academy of Agricultural Sciences) 2012

I am enormously pleased to have the opportunity to write this editorial for the inaugural issue of Agricultural Research, published by India's distinguished National Academy of Agricultural Sciences. Engineers and scientists, along with many other citizens, have been enormously inventive in creating solutions for the many problems that are encountered in everyday life. As a result, there is a great deal of distributed wisdom throughout India's 600,000 rural villages, much of it relating to agricultural practices. What seems to be lacking is an efficient way of collecting the best of this wisdom, evaluating it scientifically, and distributing the results in a form that the world can readily use to both challenge and build on. For the future of humanity, it is critical that this need be filled. This challenge represents a great opportunity for the Academy, as well as for Agricultural Research.

One example of a creative approach for improving livelihoods in rural, agriculture-based Indian villages is the work led by Dr. M.S. Swaminathan. For more than 20 years, he has led one of India's many experiments in harnessing science and technology to empower India's millions of rural poor. Since 1999, my wife and I have made periodic visits to observe Dr. Swaminathan's impressive "information village" projects in action. The scientists who have overseen these projects have been humble and realistic enough to admit that they need to learn by doing, and they have demonstrated deep respect for the intelligence and values of the villagers by using them to help shape each project. Thus, the inhabitants of a village are challenged to organize and identify their needs before being provided with a computer and wireless

B. Alberts $(\square)$

University California, San Francisco, CA, USA

e-mail: bruce.alberts@ucsf.edu
Internet connection, which must be made available to all the inhabitants-irrespective of wealth or social status. In the end, groups of women from the village generally manage the computers, providing daily weather and market prices, as well as agricultural and health information to the community. As the projects have evolved, the internet connections have been used to improve livelihoods through the development of a large number of small "science franchises"-village efforts that produce mushrooms, dairies, or biopesticides, for example-supported by loans provided by the Indian Banks to "self-help groups" and individual villagers.

The lessons learned thus far from Dr. Swaminathan's information village projects have been clearly compiled and summarized in Reaching the Unreached [2]. Its important chapter on Setting up Village Knowledge Centres for ICT-enabled Development starts as follows: "From the point of view of development, it is not technology which will be the critical factor. It is available and affordable. What will be crucial is empowering the rural poor and the marginalized with knowledge, skills and livelihood opportunities - or in other words bringing about a transformation in their economic and social status." The invaluable results and insights provided in this chapter are freely available on the Web, representing an important contribution to the promotion of agricultural advancement in rural India.

The relevant issue here, from the perspective of the National Academy of Agricultural Sciences, is how Agricultural Research can contribute to the absolutely critical endeavor of "making a science out of rural development," so that powerful cycles of continuous improvement can be generated, as required for both India and the world to meet the urgent goal of feeding the hungry and reaching the unreached. For example, with support from the Bharat 
Nirman program of the Government of India, hundreds of different efforts are being made to connect India's rural villages to the Internet. We can do a much better job of learning from both their successes and their failures if scientists are challenged to carry out objective scientific analyses of these projects, compiling and publishing the data and results.

To insure a bright future for India, more prestige and resources must be assigned to scientific and engineering research that focuses on rural needs. Thus, for example, I have visited the Center for Sustainable Technologies at the Indian Institute of Science (IISc) in Bangalore, where highquality research is carried out on issues such as biomass gasification, alternative building technologies, sanitation, and water purification. I understand that similar efforts to develop sustainable technologies are also being made at various other institutions of higher learning, like the agricultural research institutes, agricultural universities and science and technology institutions. But, the resources provided for the development of sustainable technologies are vastly less than that devoted to other types of science and engineering research. Today, India is strongly increasing government investments in science and technology; as it does so, the National Academy of Agricultural Sciences, in collaboration with other major Indian science academies, should work to redress what would seem to be an imbalance in the current national research portfolio.
Science is an enormously powerful system-a vigorous community endeavor in which the knowledge accumulated over time becomes much more than the sum of its parts [1]. But for success in building a valuable store of scientific knowledge, it is essential that there be openness, an honest sharing of data and methods, and a willingness to be critical both about ones own results and the results of others. These are values that the National Academy of Agricultural Sciences is ideally situated to disseminate, thereby promoting Jawaharlal Nehru's grand vision of creating an ever stronger "scientific temper" for India. My sincere congratulations on the creation of Agricultural Research, a powerful new tool to support these efforts.

\section{References}

1. Dasgupta P (2000) Science as an institution: setting priorities in a new socio-economic context. In: Science for the twentieth century: a new commitment. UNESCO, pp 264-271

2. Nanda S, Arunachalam S (2009) Reaching the Unreached: Community based Village Knowledge Centres \& Village Resource Centres. Jamsetji Tata National Virtual Academy (NVA), M S Swaminathan Research Foundation. http://www.suchit.net/books/ Reaching-the-Unreached.pdf 